\title{
Positioning and Stabilizing Of an Inertial System Subjected To Oscillatory Disturbance Using Electro- Hydraulic Control
}

\author{
Dr. Zakariva Yahva Mohammad Ahmed Fattah Ahmed \\ Mechanical Engineering Department \\ College of Engineering \\ University of Mosul
}

\begin{abstract}
In this work, a control system for positioning and stabilizing a massive inertial system subjected to continuous disturbances, which represents the oscillatory motion of the base, is investigated. A hydraulic system is proposed and simulation is used to select and test the effect of different parameters of the hydraulic parts, particularly those of the electro - hydraulic servo valve, at different values of the supply pressure of the hydraulic fluid.

The inertial system dynamics and the hydraulic parts are mathematically modeled and simulated by digital computer using (MatLab). The dynamic characteristics of the control system, such as the stability and the time response in addition to the ability of the system to reduce the effect of the external disturbances are examined. The results show that the control system is capable of reducing these effects between (70\% to $90 \%$ ) depending on the supply pressure of the hydraulic system and the frequency of the external disturbances. In addition, the effect of using pressure limit valve in the hydraulic system and that of the presence of dry friction of a relatively high value, are investigated.

Keywords: position control, hydraulic system, stabilization of inertial system, Electro-Hydraulic Control

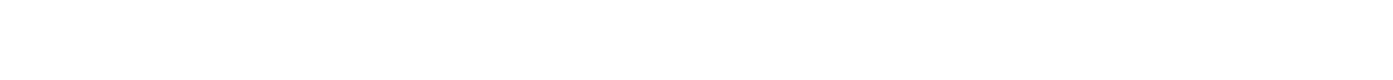

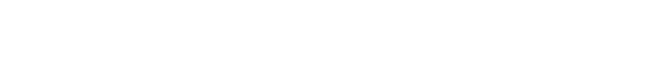

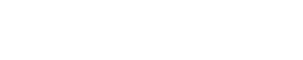

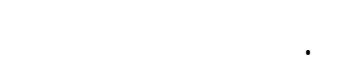

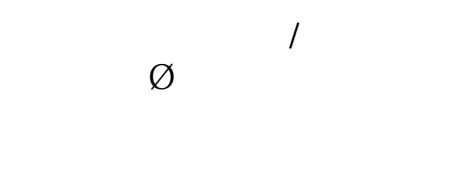

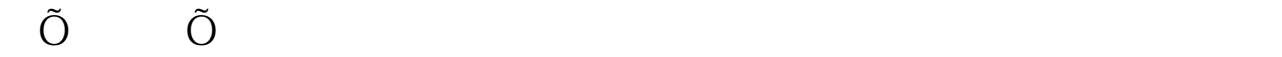

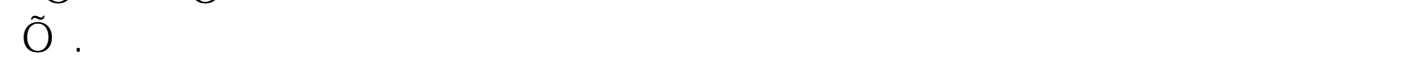

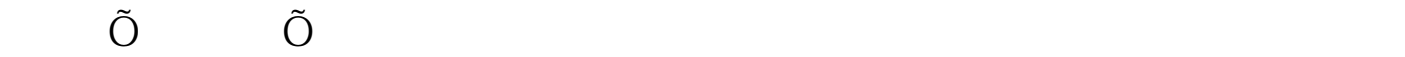

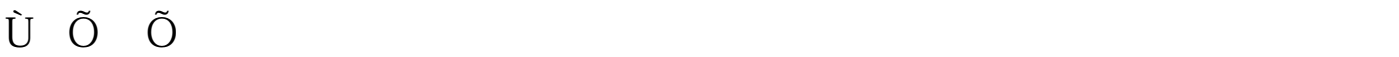

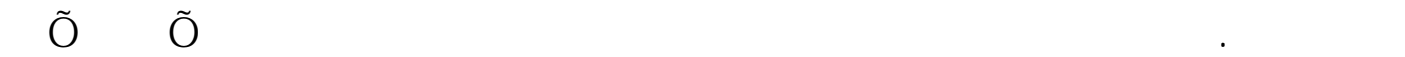

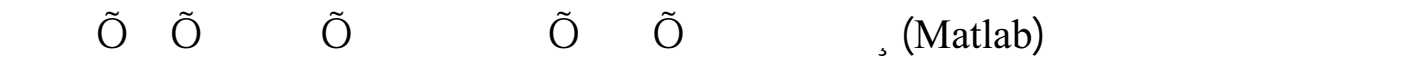

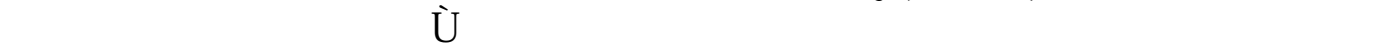

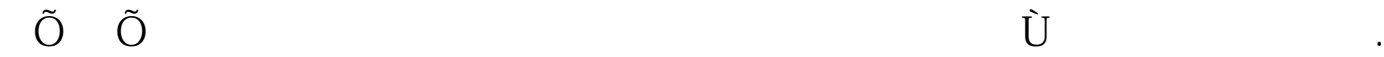

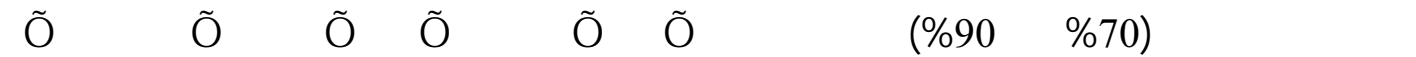

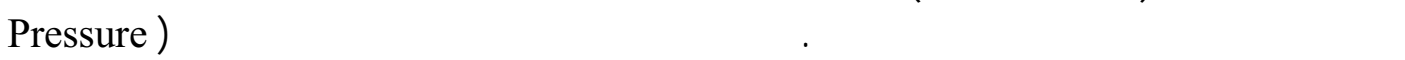

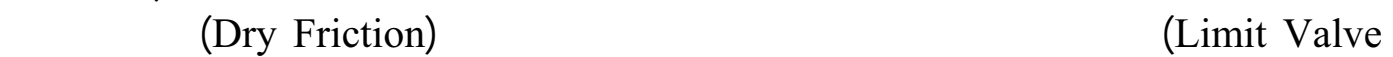

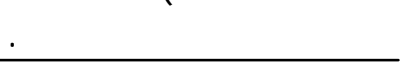




\section{Introduction:}

The application of feed back control system for positioning and stabilizing inertial systems range from that for changing and controlling the direction of large masses such as ships $[2,3]$, the positioning and fine adjusting robot arms such as that used in industry, medical equipments and medical surgery $[1,7]$.

The power devices or the actuators, for different application, are selected according to the inertial values of the body to be positioned. For low or moderate inertial values an electrical or pneumatic actuator may be useful. For Bodies with a relatively large inertia, a hydraulic actuators and relevant devices should be necessary.

However, the positioning of large inertial systems has been considered as an important object when stability, accuracy and response fastness are needed. These gathered requirements become more critical when external disturbances of any type, is acting on the system. The cost of this kind of systems is high and there is a need, as in other control system, to build the mathematical model and to examine the performance of the complete system by simulation.

\section{The Dynamics of the System and the Mathematical Model:}

The inertial system, here, is a body of high mass moment of inertia which is hinged to the base as shown in figure (1). The arrangement allows the control system actuator to derive the inertial system to the required absolute angular position $\left(\theta_{\mathbf{a b}}\right)$. On the other hand, minimization of the effect of the system disturbance represented by the oscillatory angular position of the base $(\phi)$ should be possible. Accordingly, this is performed by varying the relative angle between the base and the body $\left(\theta_{\text {re }}\right)$. The inertial system is assumed to have a general plane motion and its dynamics is governed by Newton's second low of motion.

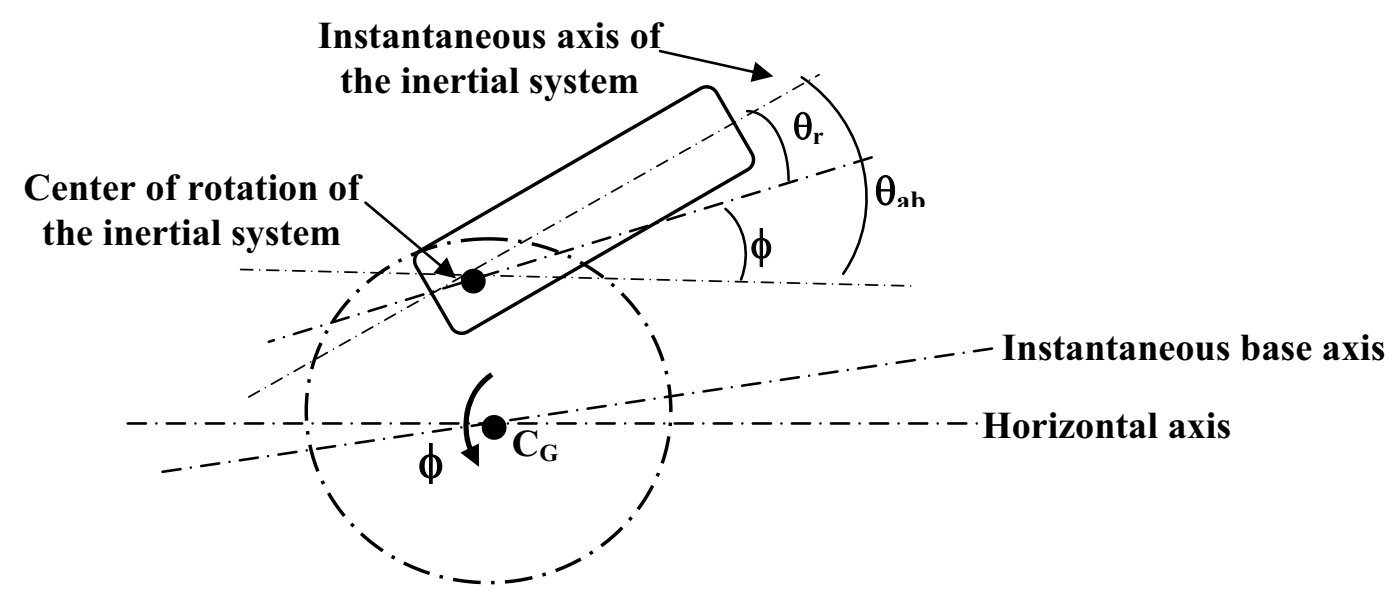

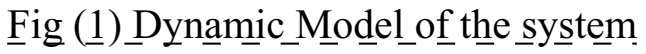


Figure (2), illustrates the main forces and torque's acting on the system. When the system has a vertical and horizontal motion, the resultant acceleration $\left(\mathbf{a}_{\mathbf{c g}}\right)$ and the gravitational acceleration $(\mathrm{g})$ will induce an additional disturbance torques about the center of rotation (o). The effect of the above mentioned disturbances on the system can almost be eliminated. Practically, this is achieved by letting the center of gravity (c.g) to coincide with the center of rotation (o).

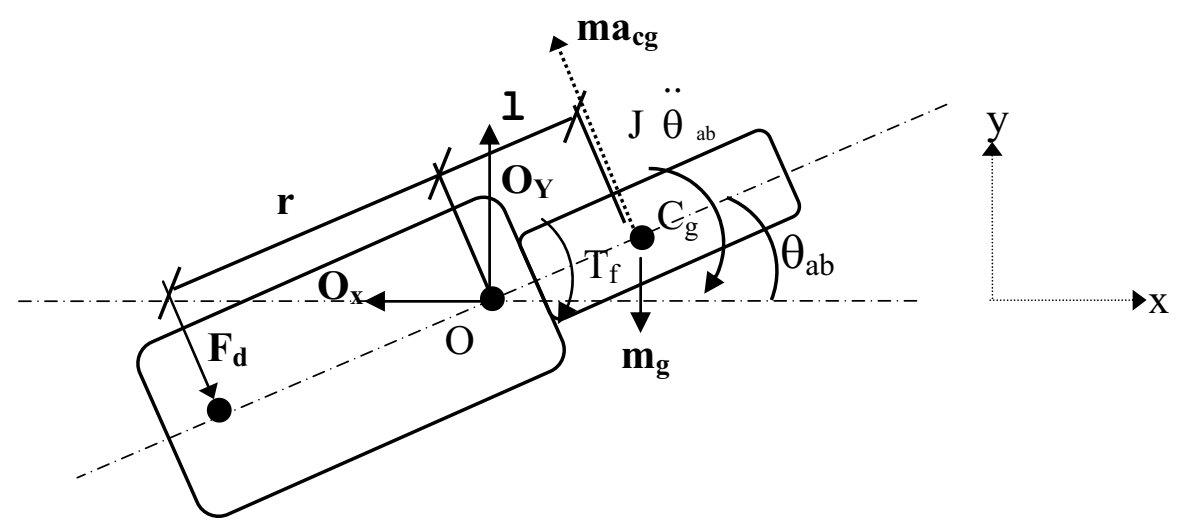

Fig (2) A Schematic of the inertial system showing the center of gravity center of rotation $(O)$ and the actuator force

Applying Newton's second law of motion on the system we have:

$\sum \mathrm{M}_{\mathrm{o}}=\mathrm{J} \ddot{\theta}_{\mathrm{ab}}$

Or

$$
\mathrm{F}_{\mathrm{d}} \cdot \mathrm{r}-\mathrm{T}_{\mathrm{f}}=\mathrm{J} \ddot{\theta}_{\mathrm{ab}}
$$

Generally, the frictional torques $\left(\mathrm{T}_{\mathrm{f}}\right)$ is due to the viscous and dry friction forces. For the case of viscous forces only, the equation of motion becomes,

$$
\mathrm{T}_{\mathrm{d}}=\mathrm{J} \ddot{\theta}_{\mathrm{ab}}+\mathrm{B} \dot{\theta}_{\mathrm{re}}
$$

Knowing that

$\theta_{\mathrm{ab}}=\phi+\theta_{\text {re }}$ where $(\phi)$ is the angular position of the base, then equation of motion may be written as,

$$
\mathrm{T}_{\mathrm{d}}=\mathrm{J} \ddot{\theta}_{\mathrm{re}}+\mathrm{B} \dot{\theta}_{\mathrm{re}}+\mathrm{J} \ddot{\phi}
$$

Or

$$
\mathrm{T}_{\mathrm{d}}=\mathrm{J} \ddot{\theta}_{\mathrm{re}}+\mathrm{B} \dot{\theta}_{\mathrm{re}}+\mathrm{T}_{\mathrm{L}}
$$


Where $\left(T_{d}\right)$ is the actuator torque and $\left(T_{L}\right)$ is the external load torque. It is worth mentioning that the mass moment of inertia $(\mathrm{J})$ is of high value, such an inertia requires a hydraulic system to produce a restoring torque $\left(\mathrm{T}_{\mathrm{d}}\right)$. Particularly, when fast response is required.

\section{The Hydraulic System:}

The hydraulic components of the system have been selected according to the previously stated requirements. The least effects of nonlinearities of such components were taken into consideration. The main components of the hydraulic part of the system are the hydraulic actuator and the servo valve. The actuator is a double acting hydraulic cylinder. The cylinder body is hinged to the inertial system which is assumed to have an angular motion ranging between $\left(-5^{\circ}\right.$ to $\left.+16^{\circ}\right)$ relative to the base axis, while the connecting rod is suitably hinged to the base. This arrangement is shown in figure (3).

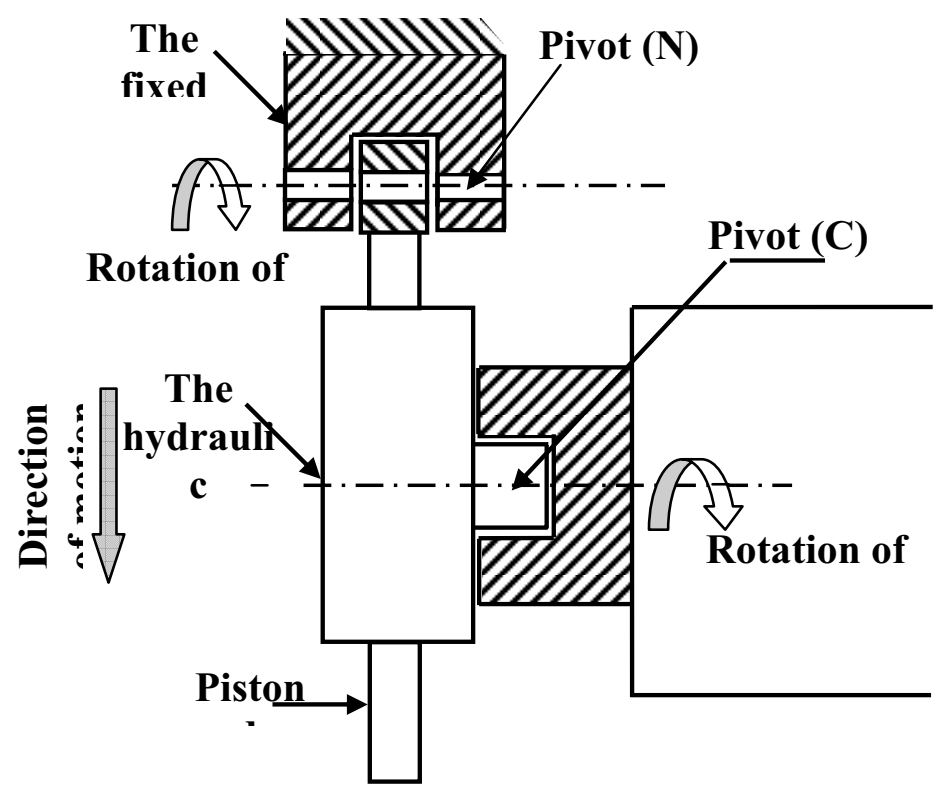

Fig (3) illustration of the connection between the hydraulic cylinder and the mass

An important component, in the proposed system, is the two stage servo valve, figure (4). This component is in fact, a hydroelectric device [5]. The electric part of which is the armature and the permanent magnet. The armature can be rotated in either direction depending on the difference between the currents $\left(\mathrm{I}_{1}\right.$ $\& \mathrm{I}_{2}$ ). This difference is calibrated with the error in the preset, or the required, angular position of the inertial system. Naturally, accurate and highly sensitive sensors, such as potentiometers, free gyros and suitable signal conditioning devices are needed to preset and measure the angular position of the base and the inertial system.

The two stages of the servo valve are the movement of the pilot valve to control the hydraulic nozzles and the movement of the spool valve to actuate the hydraulic system. 


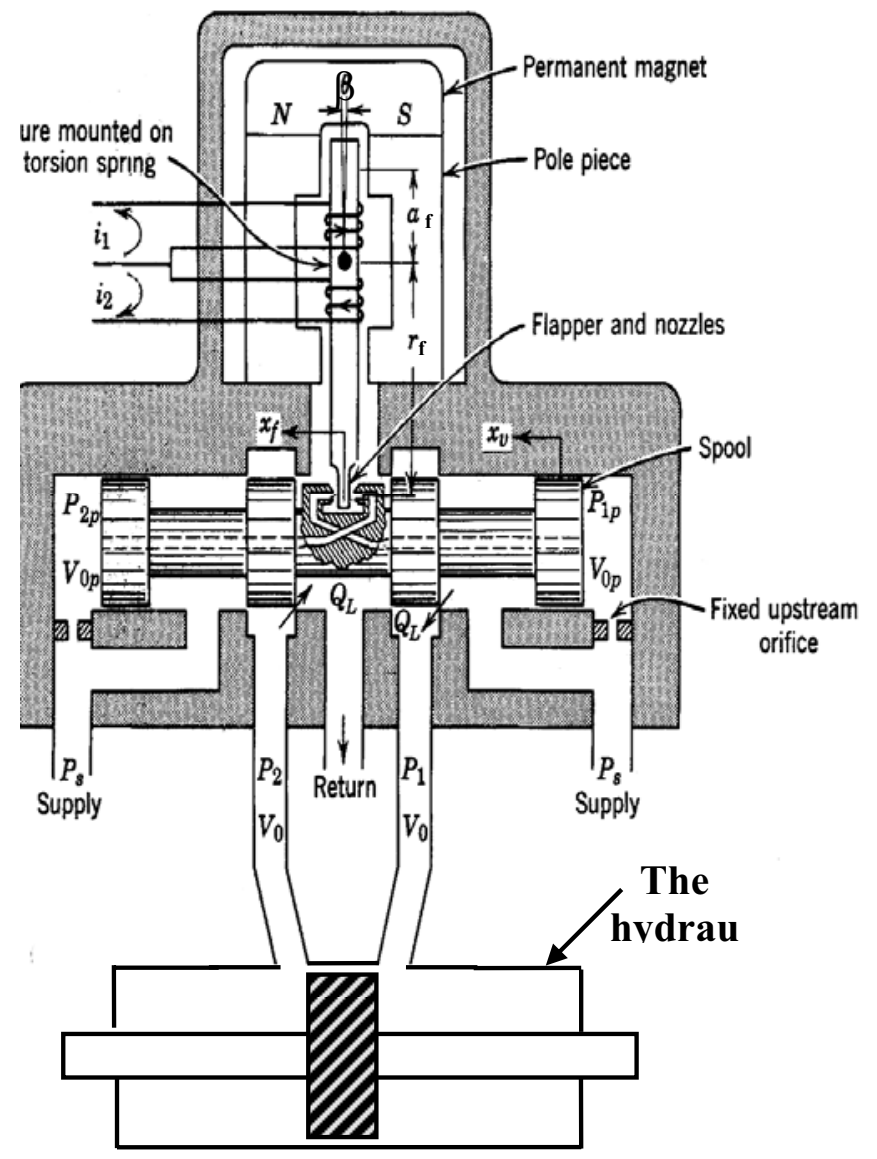

Fig (4) component of two stage hydraulic servo valve

The pilot valve is responsible for the flowing of the hydraulic fluid to the correct port. The linearized transfer function of the electromagnetic actuator controlling the inclination of this valve $(\beta)$ is given by [5]:

$$
\beta=\frac{\mathrm{k}_{\mathrm{o}} \mathrm{e}_{\mathrm{g}}-\frac{\left[1+\frac{\mathrm{s}}{\mathrm{w}_{\mathrm{a}}}\right] \mathrm{T}_{\mathrm{Lp}}}{\left[\frac{\mathrm{s}}{\mathrm{w}_{\mathrm{r}}}+1\right]\left[\frac{\mathrm{s}_{\mathrm{ae}}^{2}}{\mathrm{w}_{\mathrm{o}}^{2}}+\frac{2 \delta_{\mathrm{o}}}{\mathrm{k}_{\mathrm{ae}}} \mathrm{s}+1\right]}}{\left.\mathrm{w}_{\mathrm{o}}\right]}
$$

This inclination is affected by the electrical signal $\left(e_{g}\right)$ and the effect of the back pressure which produces the torque $\left(\mathrm{T}_{\mathrm{Lp}}\right)$ as [5].

$\mathrm{T}_{\mathrm{LP}}=\mathrm{A}_{\mathrm{N}} \mathrm{P}_{\mathrm{LP}} \mathrm{r}_{\mathrm{f}}+8 \pi \mathrm{C}_{\mathrm{df}}^{2} \mathrm{P}_{\mathrm{S}} \mathrm{X}_{\mathrm{fo}} \mathrm{X}_{\mathrm{v}} \mathrm{r}_{\mathrm{f}}$ 
The electrical signal $\left(\mathrm{e}_{\mathrm{g}}\right)$ is a linear measure of the angular error. This signal is induced to a series of suitable potentiometer $\left(\mathrm{K}_{\mathrm{pot}}\right)$, electronic amplifier $\left(\mathrm{K}_{\mathrm{am}}\right)$ and electro-magnetic actuator of gain $\left(\mathrm{K}_{\mathrm{o}}\right)$.

Where $\left(\mathrm{K}_{\mathrm{o}}\right)$ is the gain of the electro-magnetic part, $\left(\delta_{\mathbf{o}}\right)$ is the damping ratio of the electro-magnetic actuator, $\left(\omega_{\mathbf{a}}, \omega_{\mathbf{o}}\right.$ and $\left.\omega_{\mathbf{r}}\right)$ ar e the frequencies of the electro-magnetic part. $\left(\mathrm{K}_{\mathrm{ae}}\right)$ is the effective stiffness coefficient of the pilot element.

Having described the system components and the principle of operation shown in figure (5), a complete and detailed block diagram of the system is shown in figure (6).

Clearly the input and the output are the required and the actual angular positions of the inertial system respectively. A major requirement of the system performance is it's capability of reducing the effect of base angular disturbance $(\phi)$ on the output $\left(\theta_{\mathbf{a b}}\right)$.

The block diagram contains many coefficients constants and parameters. The numerical values of which have been selected according to the design requirements and the performance of the system. Extensive calculations based on design formulie have been performed $[4,5]$ to obtain the final values of these parameters and coefficients. The numerical values of these parameters, coefficients and the transfer functions are listed in table (1), for different operating supply pressures of the hydraulic fluid.

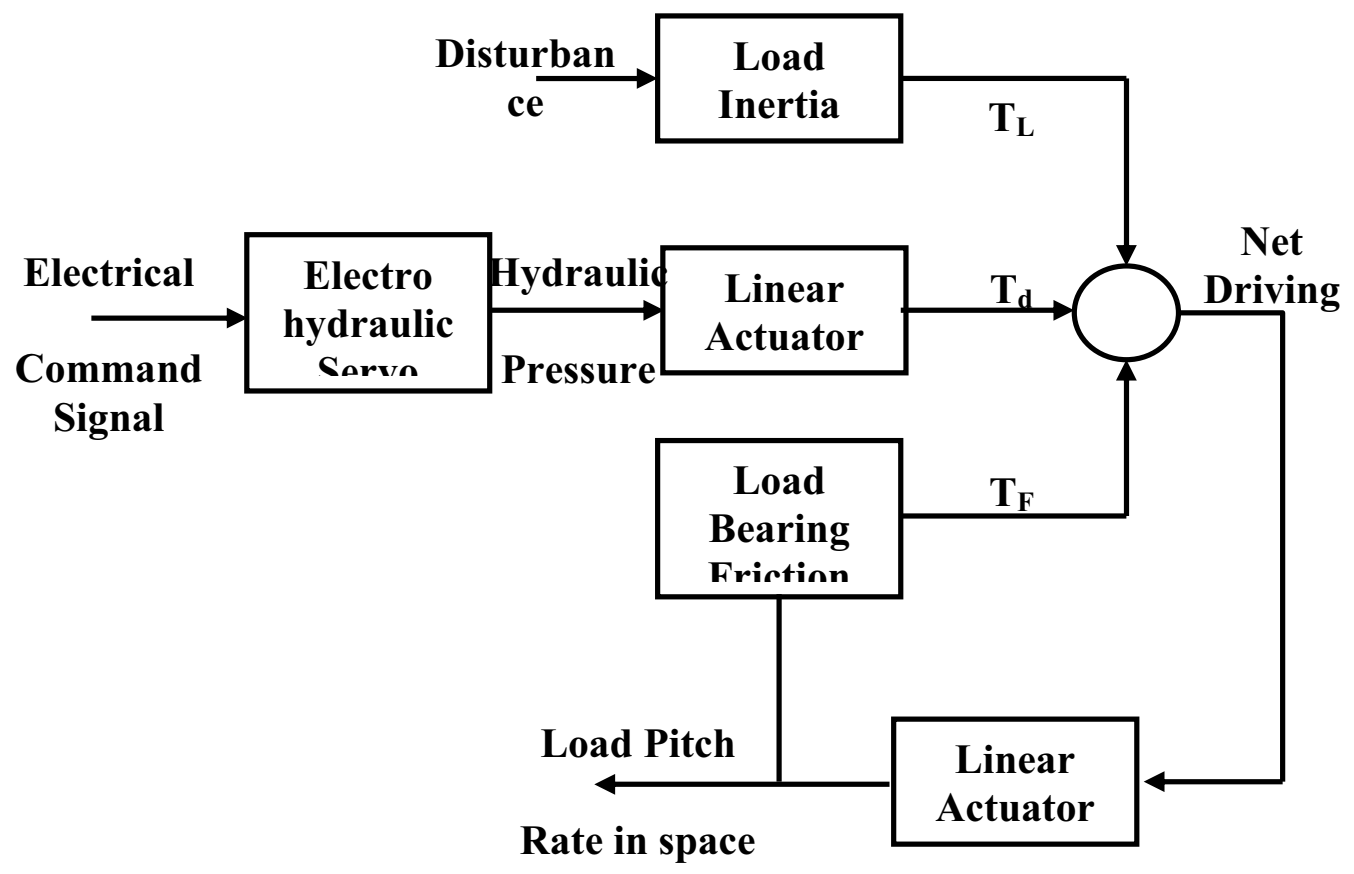

Fig (5) The principle of the system operation 


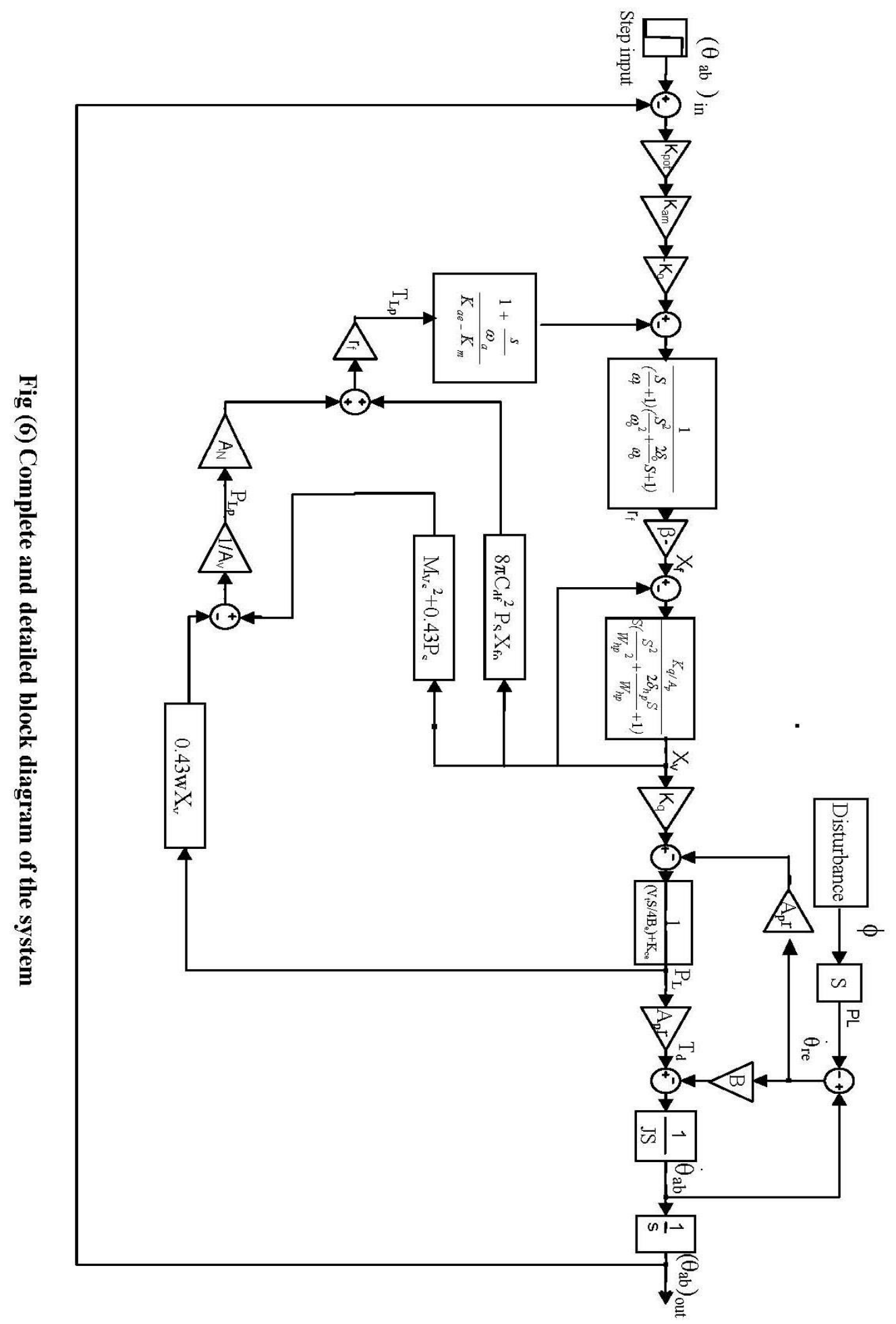




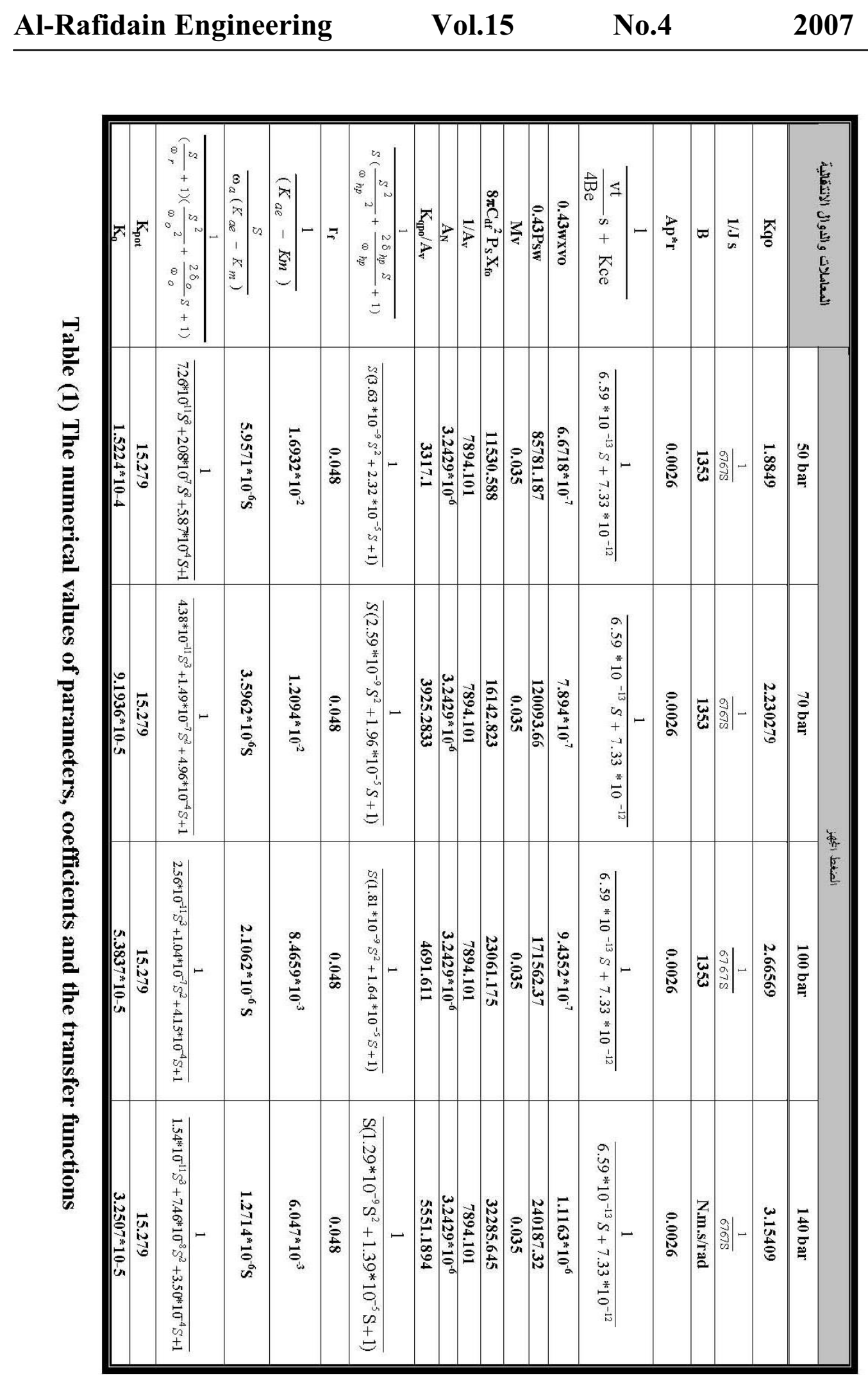




\section{Stability of the System:}

It is necessary to examine the stability of the system priore to the running of the simulation. It is found that the value of the pilot valve stiffness $\left(\mathrm{K}_{\mathrm{a}}\right)$ plays a major role in the stability of the system, this has been checked by plotting the over all system poles on the complex plane. The system is unstable when $(\mathrm{Ka})$ is taken $(25 \%)$ of its initially selected value.

When this value is increased to $(75 \%)$ of the initially selected value, the system becomes stable for the whole range of supply pressure. A typical plot of the system poles is shown in figure (7).

It may be noticed that a pair of these poles are located near by the imaginary axis. However, such a result is expected because the primary calculation concerning the servo valve are taken for the critical central zone of it's operation.

This leads to a small value of the hydraulic damping ratio $\left(\delta_{\mathbf{h}}\right)$, which increases as the system starts to operate leading to a better stability of the system in operation $[5,6]$.

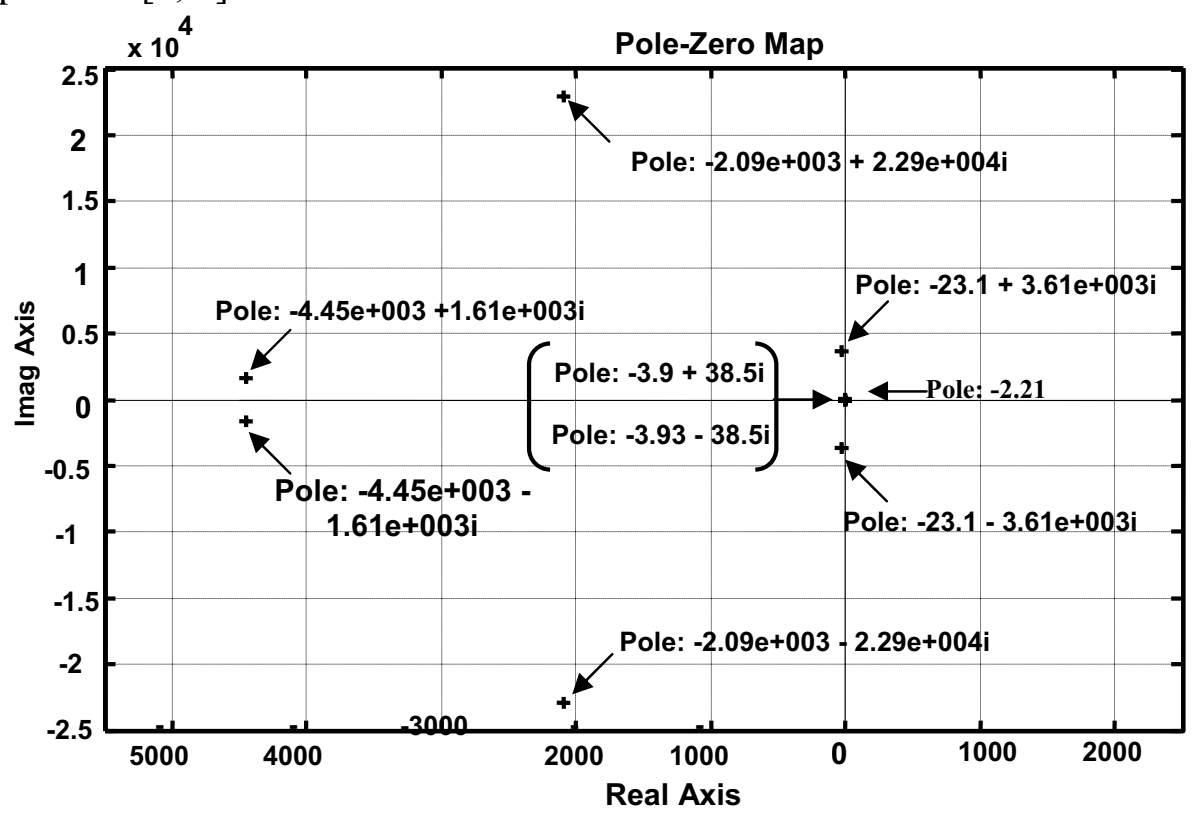

Fig (7) pole of the complete control system for supply-pressure of (100) bar

\section{The Time response of the System:}

Initially, the performance of the system is examined without external disturbances, at different supply pressures, $(50,70,100 \& 140)$ bar. With a step change of the required position $\left({ }^{\theta_{\mathbf{d}}}\right)$ no oscillation were noticed on the output position, and for $(5 \%)$ error, the settling time were observed to be $(1.956,1.65,1.38$ $\&$ 1.16) sec., for the used pressures respectively. Clearly, the higher is the pressure, the smaller will be the settling time. It is noticed that the transient response is super imposed by fluctuation. This is clearly shown in figure (8). 


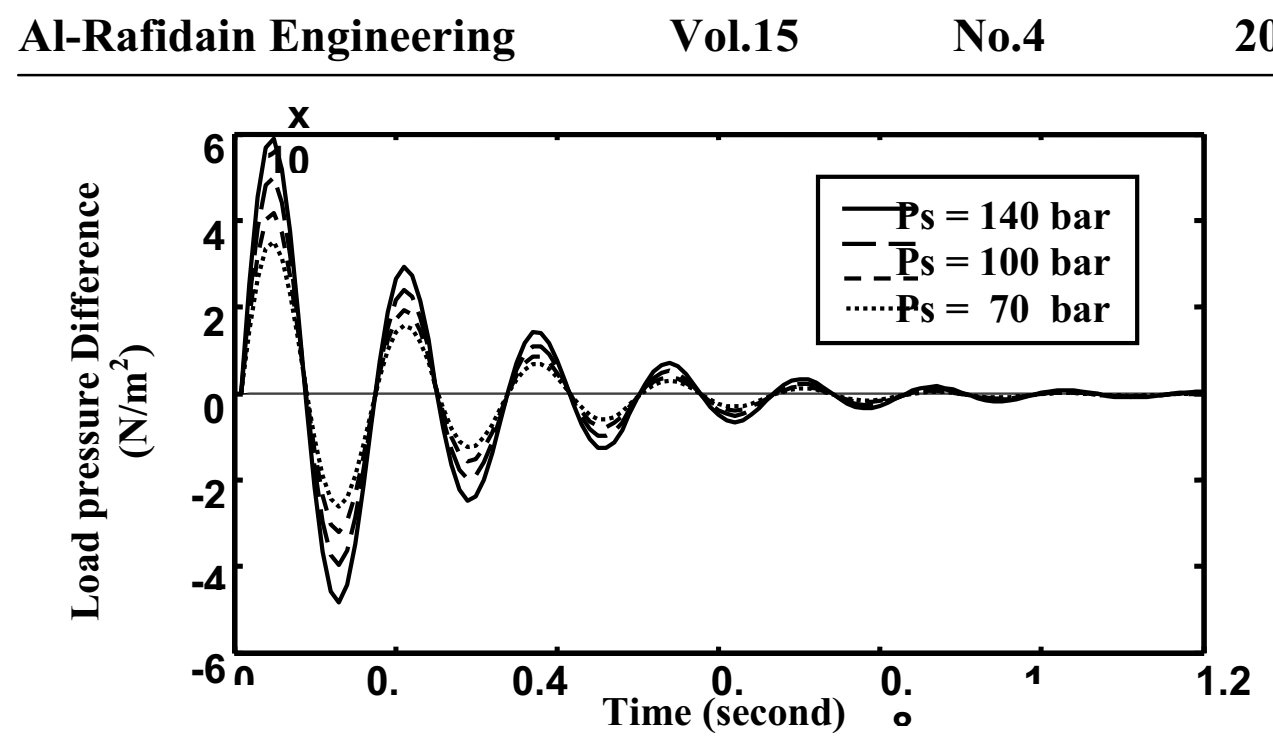

Fig (8) variation of load pressure for a leakage factor of $\left(K_{\mathrm{ce}} 7.3302 \times 10^{-12}\right)$

At the beginning, the load pressure increases to a high value in the forward chamber and to a lower value in return chamber of the actuator. This is expected because of the massive inertia of the moving load. The pressure continues to fluctuate up and down for a bout one second due to the elastic effects of the fluid.

This kind of fluctuation of the pressure, in practice, may cause a damage to the hydraulic system. For this reason, a pressure limit valve is considered necessary. It is inserted in the system in order to limit the pressure values not to rise above that recommended by the designer. The effect of this limitation on the system performance is also investigated. However, it is found possible to reduce the fluctuation of the pressure and hence that of the angular position of the inertia by altering some relevant parameters of the hydraulic system. This is achieved by increasing the diametral clearance $\left(r_{c}\right)$ and hence, the so called leakage factor (Kce) which, implicitly, increases the hydraulic damping ratio $\left(\delta_{\mathbf{h}}\right)$. The effect of the above mentioned parameter on the performance is shown in figures (9) \& (10). In practice, the leakage factor (Kce) can be changed by adjusting a suitably chosen needle valve

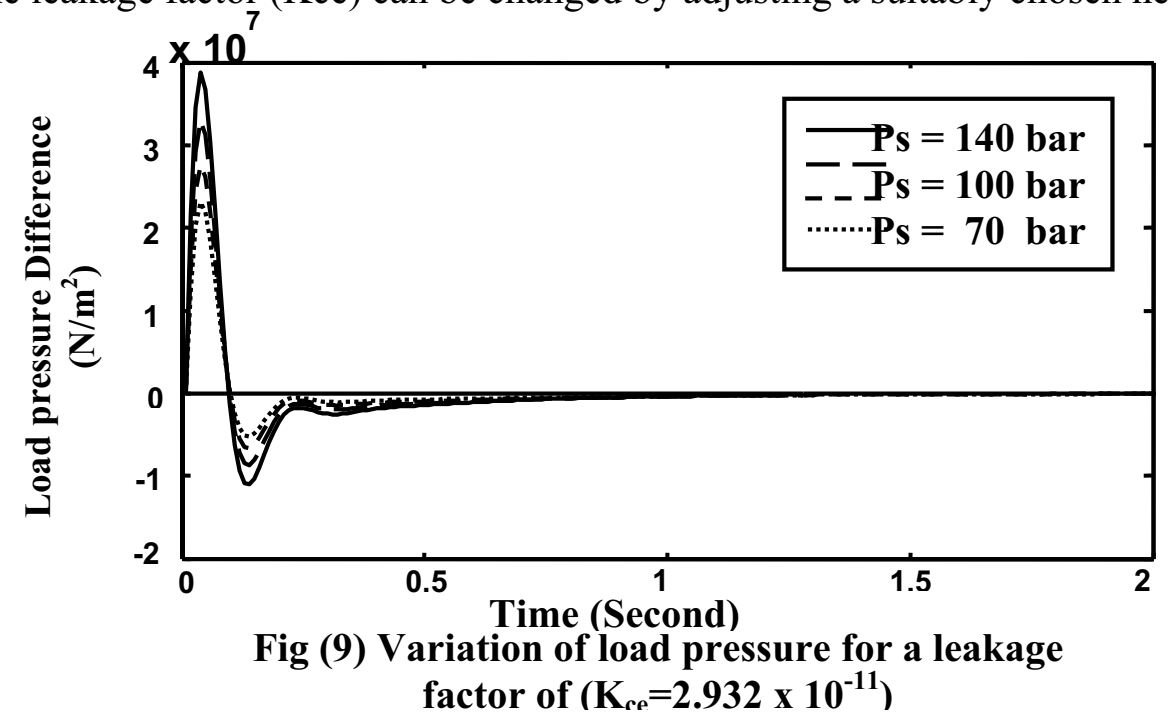




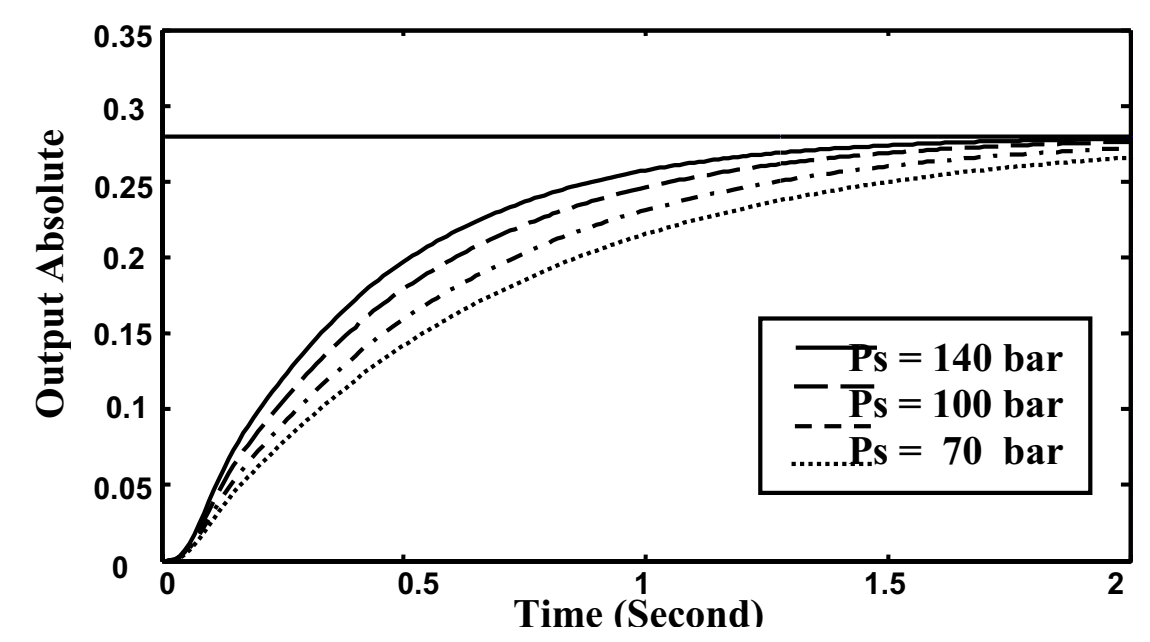

Fig (10) The time response of inertial system for a leakage factor $\left(K_{\mathrm{ce}}=2.932 \times 10^{-11}\right)$

Connecting ports of the hydraulic actuator [5], increasing the leakage factor (Kce) by factors between $(50 \%$ to $200 \%)$ results to less fluctuation in the load pressure. This is typically shown in figure (11) for a supply pressure of (100 bar).

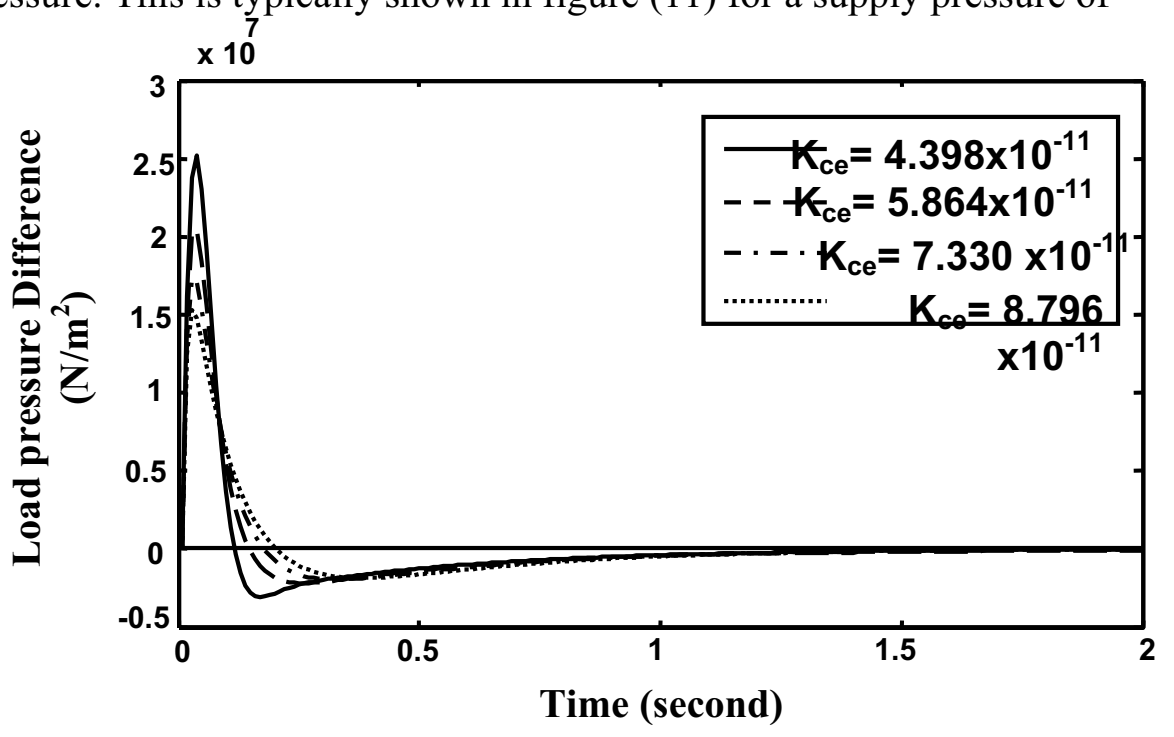

Fig (11) Variation of load pressure for different leakage factor at supply pressure of (100) bar

Obviously, the settling time increases as $\left(\delta_{\mathbf{h}}\right)$ increases. This was noticed to increase from (1.65) to (1.89) sec for a supply pressure of (100 bar). However, this fast fluctuation of the load pressure should not severely affect the motion of the massive inertial system. For a response with no oscillation of the inertial mass and small steady state error see figure (12). The amplifier gain for a recommended displacement $0 \mathrm{f}(0.6 \mathrm{~mm})$ was found to depend on the supply pressure this is typically (80.62) for (100bar). 


\begin{tabular}{llll} 
Al-Rafidain Engineering & Vol.15 & No.4 & 2007 \\
\hline
\end{tabular}

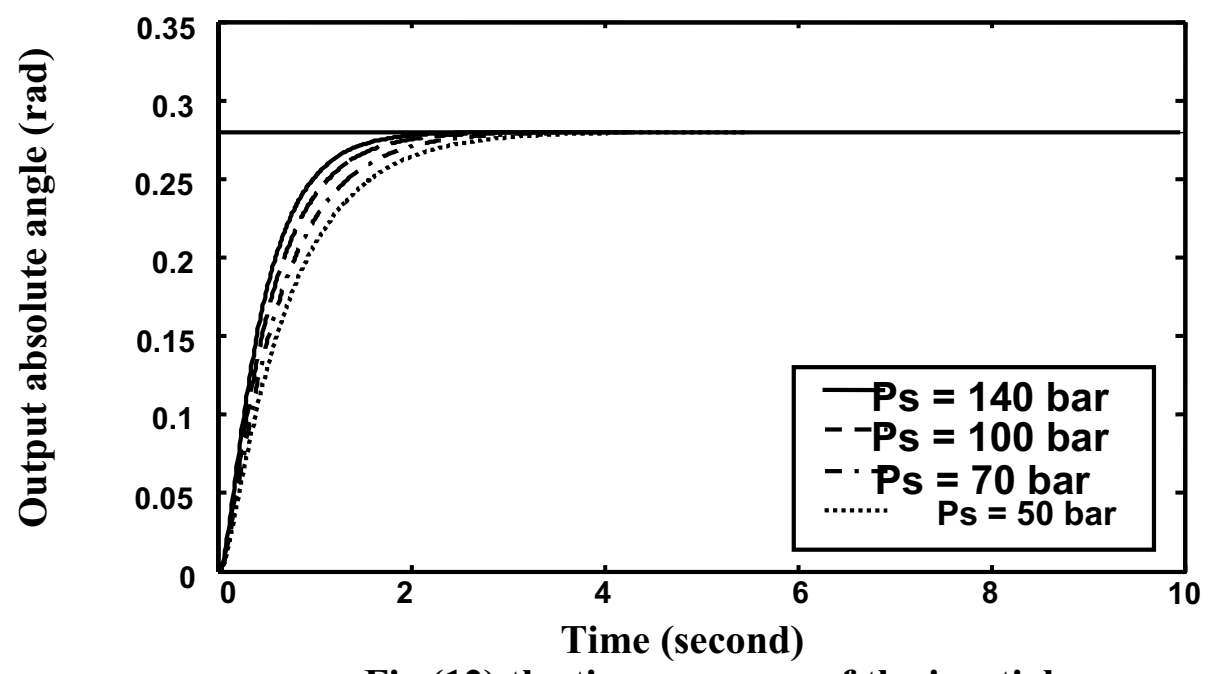

Fig (12) the time response of the inertial system with different supply pressure

\section{The Effect of the External Disturbance on System Performance:}

The capability of the system to minimize the effect of the external disturbance on the desired position is investigated. This disturbance is represented by an angular sinusoidal oscillation of the base $(\phi)$. The magnitude of which is $(0.0873$ rad), (5 degree), at different frequencies.

The required input is taken as a step function of $(0.175 \mathrm{rad}),(10$ degree $)$, This input represents the absolute angle through which the inertial system is positioned. With a frequency of (0.2) rad / sec of the external disturbance the control system is capable of reducing it's effect on $\left(\theta_{\mathbf{a b}}\right)_{\text {out }}$ to more than $(85 \%, 87 \%, 89 \%$ \& $91 \%)$ for supply pressures of $(50,70,100 \& 140)$ bar respectively, figure (13). For a frequency of $(0.45) \mathrm{rad} / \mathrm{sec}$ the reduction was found to be more than $(67 \%$, $71 \%, 75 \% \& 78 \%$ ) for the same supply pressures, figure (14) .

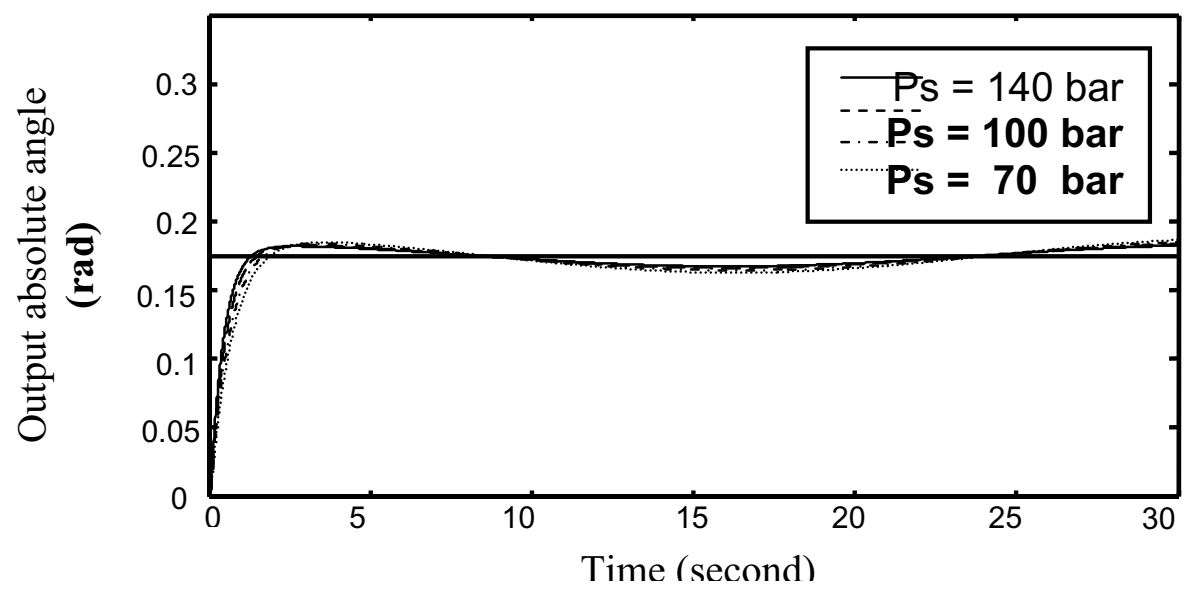

Fig (13) the time response of the inertial system with sinusoidal base disturbance of $(0.2 \mathrm{rad} / \mathrm{s})$ 


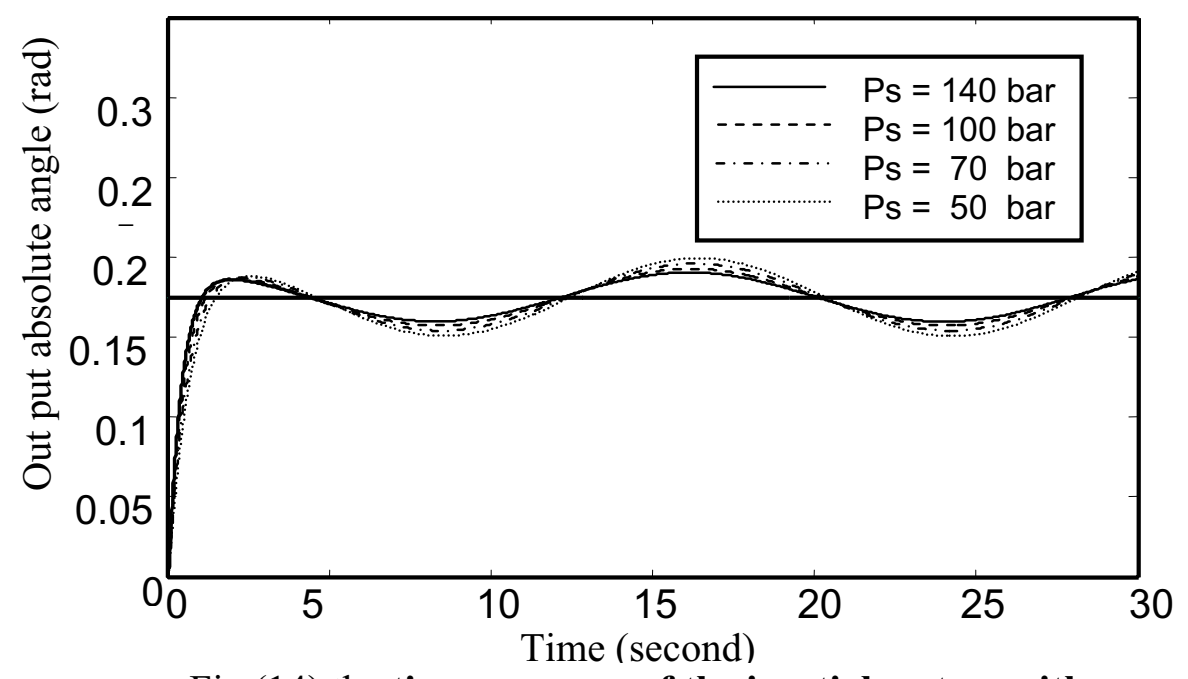

Fig (14) the time response of the inertial system with sinusoidal base disturbance of $(0.45 \mathrm{rad} / \mathrm{s})$

Clearly, this reduction depends on the frequency of the angular disturbance and the supply pressure of the hydraulic fluid. Less reduction was noticed for a frequency of $(0.65) \mathrm{rad} / \mathrm{sec}$, figure (15). However, at this frequency of the disturbance, more than $(71 \%)$ can be achieved with suitable supply pressure.

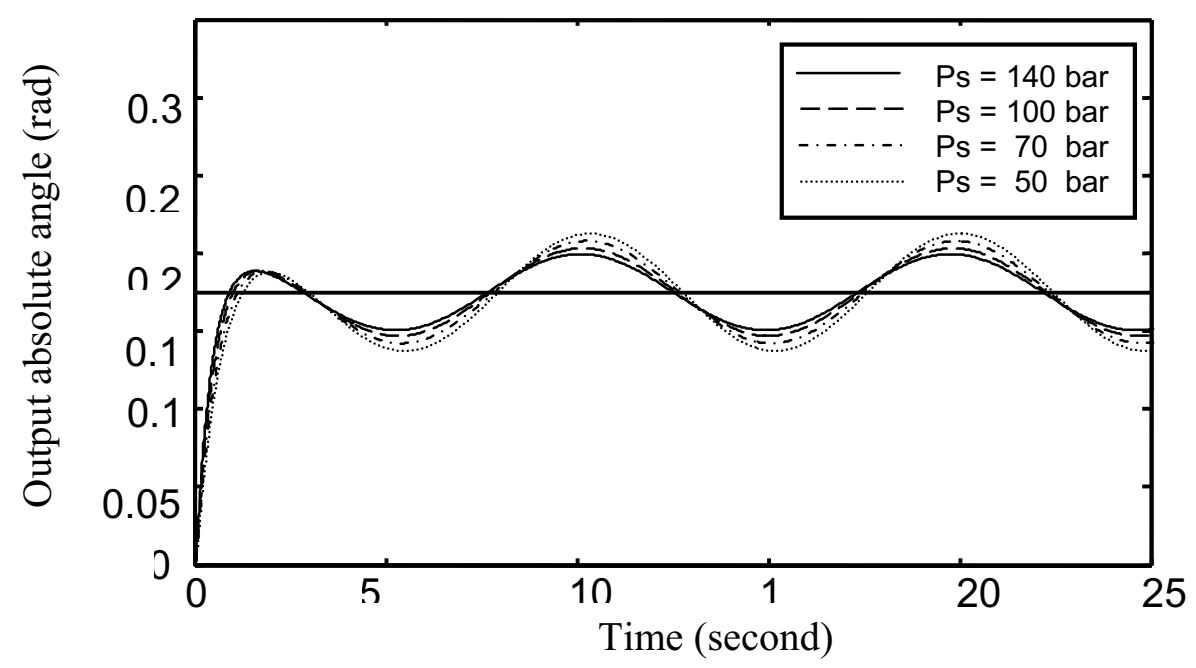

Fig (15) the time response of the inertial system with sinusoidal base disturbance of $(0.65 \mathrm{rad} / \mathrm{s})$ 


\begin{tabular}{llll} 
Al-Rafidain Engineering & Vol.15 & No.4 & 2007 \\
\hline
\end{tabular}

\section{The effect of using pressure limiting devices on the time response of the system:}

Pressure limiting devices are normally used in hydraulic system. These devices limit the oscillating load pressure from going higher than the supply pressure. The time response of the system when the pressure is limited to that of the supply is shown in figure (16), typically, for a supply pressure of (100) bar and a required position of (0.279) rad.

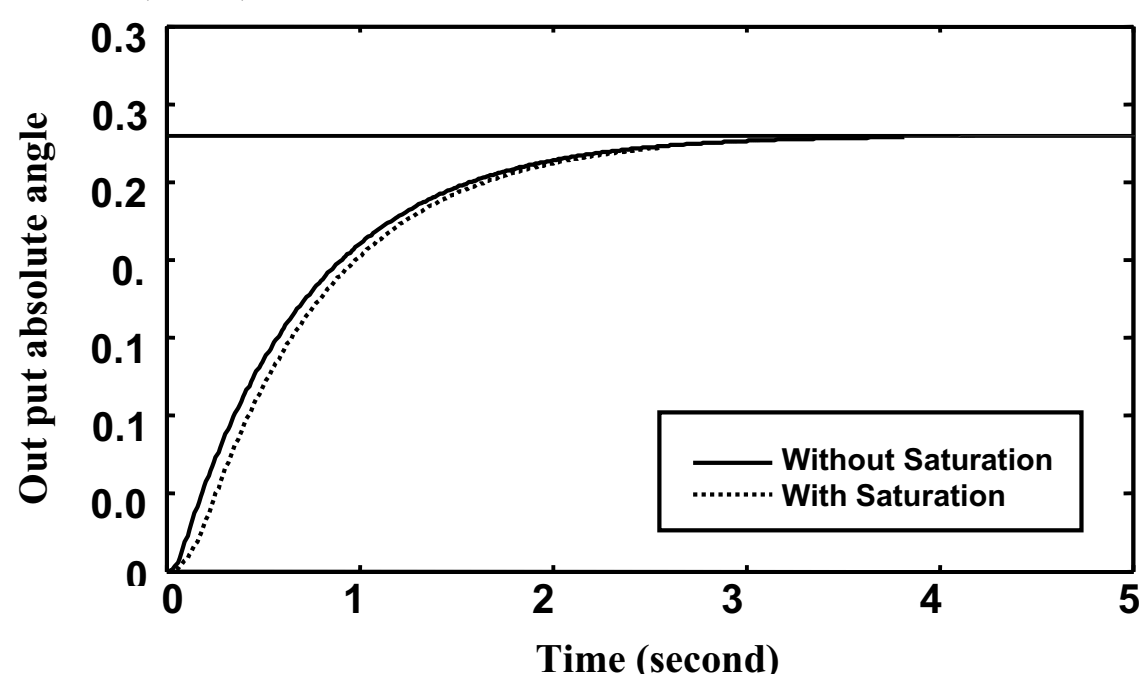

Fig (16) The effect of pressure saturation or supply pressure limit of (100 bar)

Upon examining the effect of the pressure limit, or saturation, on the time response in the presence of external disturbance, the result shows that the response is almost the same with that when no pressure limit is used. This is typically shown in figure (17), for a supply pressure of (70 bar).

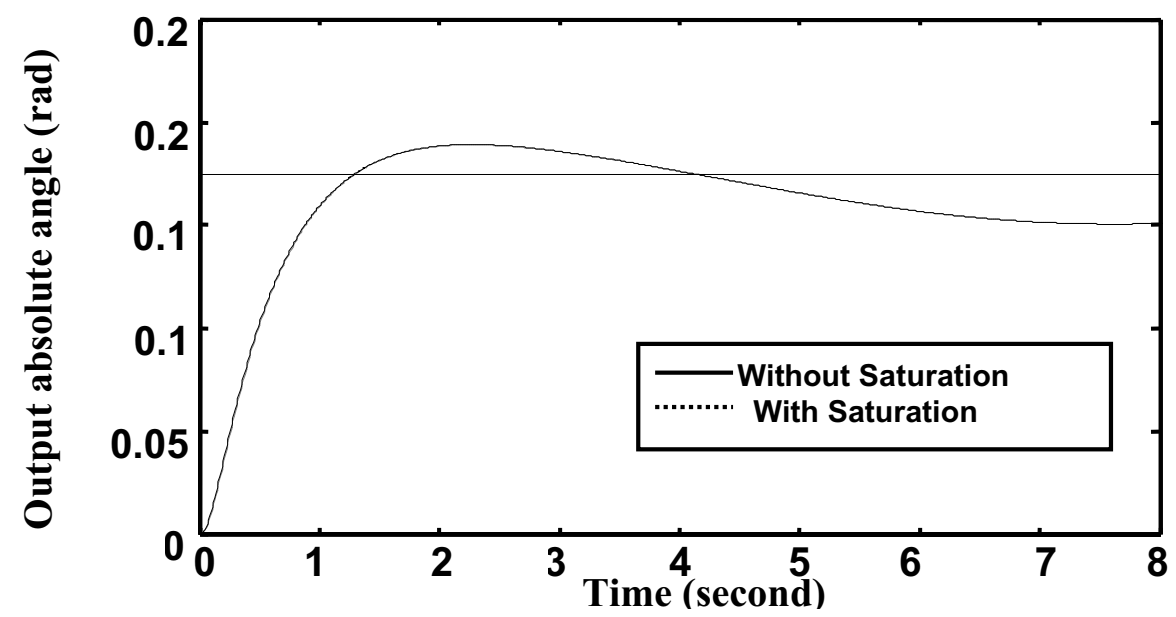

Fig (17) the time response of inertial system with sinusoidal disturbance of the base of $(0.45 \mathrm{rad} / \mathrm{s})$ at a pressure limit of $(70 \mathrm{bar})$ 


\section{The Effect of Coloumb Friction on the Performance:}

Although, in the design stage of system hardware, the dry friction between the moving elements is minimized, an amount of this kind of friction will always be present and normally increases with aging and operation. The effect of which is investigated for an amount of $(10 \%)$ and $(20 \%)$ of the maximum value of the driving couple which are relatively high values. A plot showing the effect of coloumb, or dry frictions is shown in figure (18) for a supply pressure of (70 bar) in the presence of sinusoidal external angular disturbance of $(0.083) \mathrm{rad}$ and $(0.2) \mathrm{rad} / \mathrm{sec}$ frequency. Clearly for more friction, the steady state error in the position is slightly increases. This is shown, when the dry friction is doubled. An amount of steady state error is expected since the presence of coulomb friction sets the system to some nonlinearity.

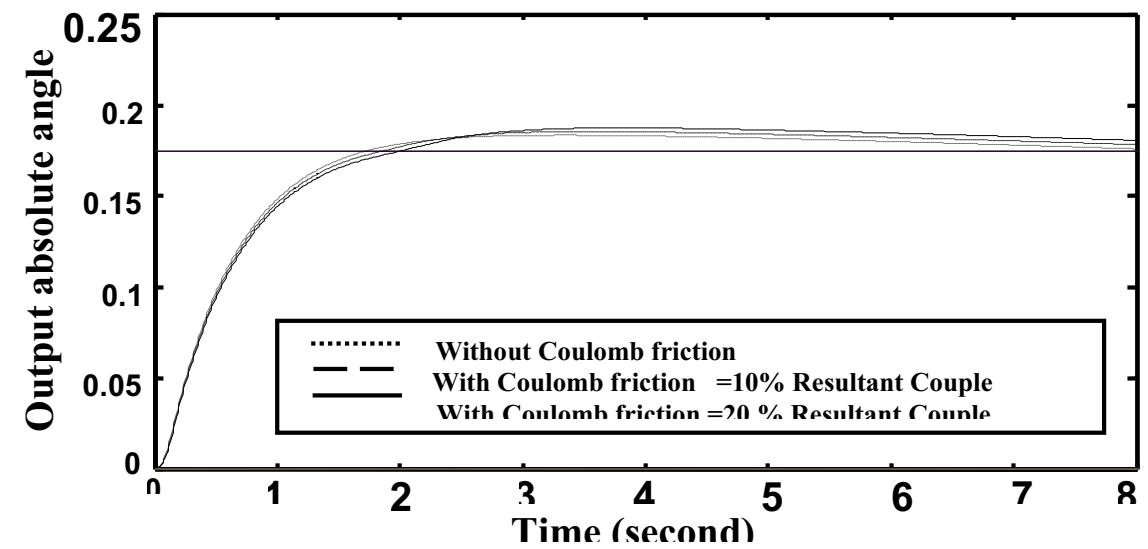

Fig (18) the effect of dry-friction on the positioning of the inertial system with a sinusoidal disturbance of $(0.2 \mathrm{rad} / \mathrm{s})$ with a limit of supply pressure of (70 bar)

\section{Conclusions}

The following Points can be observed from the obtained result.

- The stability of the system, in operation, is influenced by the stability of the first stage in the servo valve. The stability of this stage can be obtained by a suitable selection of the stiffness of the pilot element.

- The oscillation of the pressure in the hydraulic system, and hence that in the position of the inertial body can be effectively reduced or dominated by increasing the leakage factor in the hydraulic actuator, this would increase the damping ratio in the hydraulic part of the system. Thus, the oscillatory pressure due to the elastic effects of the liquid is damped.

- The fastness of the response increases when the supply pressure increases. This is, also, affected by limiting the pressure or saturation. The capability of the system in rejection the system disturbance depends on both the supply pressure and the frequency of the disturbance.

- The dry friction between the moving parts of the system increases the steady state error in the required position. 


\begin{tabular}{llll} 
Al-Rafidain Engineering & Vol.15 & No.4 & 2007 \\
\hline
\end{tabular}

\section{Notation}

$\begin{array}{cl}\delta_{h} & \text { Hydraulic damping ratio } \\ \mathrm{K}_{\mathrm{ce}} & \text { Leakage factor } \\ \mathrm{a}_{\mathrm{cg}} & \text { Resultant acceleration } \\ \mathrm{g} & \text { Gravitational acceleration } \\ \theta_{a b} & \text { Absolute angle } \\ \theta_{r e} & \text { Relative angle } \\ \phi & \text { Angular position of the base } \\ \mathrm{J} & \text { Mass moment of inertia } \\ \mathrm{T}_{\mathrm{f}} & \text { Friction torque } \\ \mathrm{T}_{\mathrm{d}} & \text { Actuator torque } \\ \mathrm{F}_{\mathrm{d}} & \text { Restoring torque } \\ \mathrm{T}_{\mathrm{l}} & \text { External load torque } \\ \mathrm{T}_{\mathrm{Lp}} & \text { Back pressure load torque affecting the flapper valve } \\ \mathrm{A}_{\mathrm{N}} & \text { Nozzle area } \\ \mathrm{r}_{\mathrm{f}} & \text { Distance between the center and the center of rotation of the flapper } \\ \mathrm{C}_{\mathrm{df}} & \text { valve } \\ \mathrm{P}_{\mathrm{s}} & \text { Orifice flow rate coefficient } \\ \mathrm{X}_{\mathrm{fo}} & \text { Supply pressure } \\ \mathrm{X}_{\mathrm{v}} & \text { Clearance between flapper and nozzle at null position } \\ \mathrm{K}_{\mathrm{am}} & \text { Spool valve displacement } \\ \mathrm{K}_{\mathrm{pot}} & \text { Electronic amplifier gain } \\ \mathrm{e}_{\mathrm{g}} & \text { Potentiometer gain } \\ \mathrm{K}_{\mathrm{o}} & \text { Electro-magnetic actuator signal } \\ \mathrm{W}_{\mathrm{a}}, \mathrm{W}_{\mathrm{o}}, \mathrm{W}_{\mathrm{r}} & \text { Electro - magnetic actuator gain } \\ \delta_{o} & \text { Frequencies of the electro-magnetic elements } \\ & \text { Damping ratio of the electro - magnetic actuator }\end{array}$

\section{References}

1. Gordon, M. Mair. "Industrial Rabotics", Printice-Hall International (UK) Ltd., 1988.

2. Atkinson, P., "Feedback Control Theory for Engineers", 2nd edition, William Clowes and Sons, 1974.

3. Harold, C., and Robert, W.M., "Servomechanisms and Regulating System Design", Volume I, 2nd. Edition, John Wiley and Sons, 1959.

4. Ahmed, F.Ahmed, "Automatic Positioning of Ineria System Subjected to Continues Disturbance", M.Sc. theses, Department of mechanical engineering, University of Mosul,2002.

5. Herbert, E. Meritt, "Hydraulic Control Systems", John Wiley and Sons, 1967.

6. Benjamin, C. Kuo, Farid Golnaraghi, "Automatic Control System" Eighth Edition, John Wiley and Sons, 2003.

7. Yoshihiko Takahashi, Shinobu Ogawa, "Mechanical Design and Control System of Robotic Wheelchair with Inverse Pendulum Control ", Transactions of the Institute of Measurement and Control, Vol. 24, No. 5, 355-368 (2002).

The work was carried out at the college of Engg. University of Mosul 